\title{
O PROGRAMA DA OCDE TALIS: enquadrando, medindo e vendendo professores de qualidade ${ }^{1}$
}

Tore Sorensen

Universidade Louvain, Bélgica

Susan L. Robertson

Universidade de Cambridge, Reino Unido

\begin{abstract}
Resumo
Este artigo examina o papel fundamental da Organização para a Cooperação e Desenvolvimento Econômico (OCDE) em coordenar as ações do problema da "qualidade dos professores" para a competitividade global, e o trabalho político em curso exercido pela OCDE e instituições aliadas na promoção da marca Professor de Qualidade ${ }^{\mathrm{TM}}$, por meio de uma pesquisa conhecida por Avaliação Internacional de Ensino e Aprendizagem (TALIS). Exploramos as políticas mais amplas no trabalho (docente) e as implicações do programa TALIS como uma ferramenta de construção política, processo e governança global. Ainda, mostramos uma dinâmica bifacetada no trabalho envolvendo a formação de instituições e processos em escala global para enquadrar, medir e vender uma marca particular de professor; aquele que é flexível, que privilegia o construtivismo como uma abordagem pedagógica e que usa 'evidências' para tomar decisões de ensino e aprendizagem. No conjunto, as atividades da OCDE no enquadramento, medição e venda do Professor de Qualidade ${ }^{\mathrm{TM}}$ - embora legitimada com a ideia da criação do novo professor profissional - desafia paradoxalmente a autoridade docente, realoca a governança dos professores em escala global e vende uma versão reduzida de possibilidades em relação à qualidade do professor.
\end{abstract}

Palavras-chave: Educação; Profissão Docente; OCDE

\begin{abstract}
This paper examines the pivotal role of the Organisation for Economic Cooperation and Development's (OECD) in orchestrating the framing of the problem of 'teacher quality' for global competitiveness, and the ongoing political work of the OECD and allied institutions in promoting this brand of Quality Teacher ${ }^{\mathrm{TM}}$ through its Teaching and Learning International Assessment (TALIS). We explore the wider politics at work and the implications of TALIS as a political construct, process, and global governing tool and show a dual dynamic at work involving the formation of institutions and processes at a global scale, to frame, measure and sell a particular brand of teacher; one who is flexible, privileges constructivism as a pedagogical approach, and who uses 'evidence 'to make teaching and learning decisions. Taken together, the OECD's activities in framing, measuring and selling the Quality Teacher ${ }^{\mathrm{TM}}$ - whilst legitimated as creating the new professional teacher - paradoxically challenges teacher authority, relocates the governing of teachers to the global scale, and sells a slimmed down version of possibilities regarding teacher quality.
\end{abstract}

Keywords: Education; Teach professional; OCDE

ISSN 1645-1384 (online) www.curriculosemfronteiras.org 


\section{O programa da OCDE TALIS - Enquadramento, Medição e Venda de Professores de Qualidade ${ }^{\mathrm{TM}}$}

A profissão docente tem sido objeto de debates políticos internacionais há décadas, embora, até mais recentemente, girasse em torno das condições de trabalho em ambientes subnacionais e em relação às agências que deveriam garantir o profissionalismo docente (OIT \& UNESCO, 1966; PAPADOPOULOS, 1994). Nos últimos dez anos, no entanto, isso mudou e os professores estão sob os holofotes da 'qualidade' acima da natureza de sua base de conhecimento, das suas práticas pedagógicas e se eles agregam ou não valor à aprendizagem de seus alunos (CAENA, 2014; CONNELL, 2009; Força-Tarefa Internacional sobre Professores para Educação Para Todos, 2014; MACBEATH, 2012; ROBERTSON, 2012; BANCO MUNDIAL, 2012). Tal fato equivale a uma reformulação do trabalho dos professores para a competitividade global, impulsionado por uma dinâmica dupla de desnacionalização na governança educacional (ROBERTSON \& SORENSEN, no prelo; veja também SASSEN, 2003).

O argumento posto pelas agências internacionais como a Organização de Cooperação para o Desenvolvimento Econômico - OCDE, instituição principal no engajamento da promoção do desenvolvimento econômico entre as economias desenvolvidas, é que professores podem e devem ter um papel no desenvolvimento do chamado "capital humano" (leia-se alunos) para a economia do conhecimento global, mas que a atual organização do trabalho docente mitiga contra isso. Elas alegam que precisam entender melhor o que conta como um "professor de qualidade”, bem como qual o perfil dos países em relação a essa qualidade e quais estratégias podem ser implementadas para mover o país na direção certa (SCHEICHER, 2015).

A OCDE tem desenvolvido e implementado a Pesquisa Internacional sobre Ensino e Aprendizagem (TALIS), como resposta principal para essa questão política. O Programa TALIS foca no trabalho do professor e dos diretores de escola, e representa um dos mais ambiciosos esforços, até agora, para gerar conhecimento sobre os professores. O TALIS segue um ciclo de cinco anos e já foi realizado duas vezes, com a participação de 24 e 34 países ou entidades políticas subnacionais nos anos de 2008 e 2013, respectivamente².

Baseados em pesquisa empírica (análise documental e entrevistas qualitativas com membros da OCDE, da Direção Geral da Comissão Europeia para educação e cultura, educação internacional, da união global de professores com sede em Bruxelas, Bélgica), exploramos as políticas mais amplas no trabalho (docente) e as implicações da TALIS como uma ferramenta de construção política, processo e governança global. A esse respeito, focamos no suporte dado à TALIS por duas poderosas agências globais; a Comissão Europeia, por um lado, e a Internacional da Educação (IE), por outro.

Mostramos uma dinâmica bifacetada no trabalho, envolvendo a formação de instituições e processos em escala global, para enquadrar, medir e vender um tipo particular de professor; aquele que é flexível, que privilegia o construtivismo como uma abordagem pedagógica e que usa 'evidências' para tomar decisões de ensino e aprendizagem. Nosso uso simbólico da marca Professor de Qualidade ${ }^{\mathrm{TM}}$, portanto, indica que estamos 
particularmente interessados no trabalho político da OCDE, em curso, na marca e na 'venda' da noção específica de “qualidade dos professores”. Apontando para um conjunto de paradoxos que estão emergindo em torno da governança global do Professor de Qualidade $^{\mathrm{TM}}$, concluímos que, apesar de insistir em um novo profissional, a OCDE reformula o entendimento da profissão docente nos seus próprios termos, realoca os determinantes de governabilidade para a escala global e vende uma versão reduzida de possibilidades em relação à qualidade do professor.

\section{O Programa TALIS e seus enquadramentos}

A TALIS pode ser vista como parte integrante das bases de dados dos indicadores da OCDE os quais também incluem, por exemplo, o Programa de Avaliação Internacional de Estudantes (PISA) e o Programa de Avaliação Internacional de Competências de adultos (PIAAC). No bojo do lançamento do programa PISA, a OCDE, em 2002, começou a chamar a atenção para o que eles alegam ser preocupações sobre a eficácia dos professores, argumentando que havia a necessidade de rever as tendências, dentre os membros e países associados à OCDE, a fim de identificar opções políticas para atrair, desenvolver e manter professores eficazes (OCDE, 2005). A partir disso, um dos objetivos a ser alcançado pela OCDE é o desenvolvimento dos indicadores com os professores e o ensino, que pode acontecer paralelo ao dos alunos. Em conjugação, a esperança era que esses complexos conjuntos de indicadores globais pudessem impulsionar a formulação de políticas educacionais globalmente.

O programa TALIS envolve dois questionários, direcionados a professores e diretores de escolas. O primeiro grupo das amostras é composto por aqueles que trabalham em escolas de nível 2 da ISCED. Ainda assim, os países ou regiões participantes também recebem a 'opção internacional' para incluir os níveis 1 e 3 da ISCED ${ }^{3}$. 24 países ou regiões participaram da primeira rodada do TALIS e 34, da segunda. A União Europeia está bem representada com 16 e 19 países ou regiões-membros participando das duas rodadas, respectivamente. Dentre os participantes do TALIS 2013 que não compõem a União Europeia incluem, por exemplo, Abu Dabi (Emirados Árabes Unidos), Alberta (Canadá), Brasil, República da Coreia, Malásia, México e Estados Unidos. Assim como o PISA, o TALIS também tem alcançado sucesso, pois tem atraído países não membros da OCDE a participarem. Em 2013, dez países não membros da OCDE participaram.

O principal objetivo do TALIS é posto da seguinte forma: O objetivo geral é promover indicadores internacionais fortes, bem como fazer uma análise relevante de políticas sobre professores e ensino de forma oportuna e econômica. Esses indicadores ajudam os países a reverem e a desenvolverem políticas próprias a fim de promover condições para um ensino e aprendizado de alta qualidade. As análises entre países dão oportunidades às nações que enfrentam situações similares a aprenderem sobre diferentes abordagens e seus impactos no ambiente de aprendizagem nas escolas (OECD, 2014a, p. 27; quase idêntico com a OECD, 2009, p. 19). 
A Tabela 1 apresenta uma visão esquemática geral do escopo e os principais temas políticos nas duas primeiras rodadas do TALIS. Indica também quatro características gerais do TALIS: (a) A pesquisa expandiu o foco nos professores e relativamente diminuiu nos diretores das escolas, indicados pelo número de índices e itens; (b) o TALIS busca ser mais amplo em sua cobertura nas questões-chave em relação ao trabalho docente; (c) existe um grande número de continuidade na cobertura dos temas políticos; e (d) A União Europeia tem tido uma forte influência na escolha desses temas.

Tabela 1. O escopo e os temas políticos da TALIS

\begin{tabular}{|c|c|}
\hline TALIS 2008 & TALIS 2013 \\
\hline $\begin{array}{l}\text { Escopo: } \\
\text { - } 10 \text { índices e } 43 \text { itens no questionário do professor } \\
\text { - } 13 \text { índices e } 47 \text { itens no questionário principal }\end{array}$ & $\begin{array}{l}\text { Escopo: } \\
\text { • } 14 \text { índices e } 60 \text { itens no questionário do professor } \\
\text { • • } 11 \text { índices e } 39 \text { itens no questionário principal }\end{array}$ \\
\hline $\begin{array}{l}\text { Três temas principais: } \\
\text { - liderança escolar } \\
\text { - Avaliação e feedback para professores } \\
\text { - Práticas de ensino, crenças e atitudes } \\
\text { + Desenvolvimento profissional docente como “um } \\
\text { tema importante” devido a sinergias com três temas } \\
\text { principais e o interesse da União Europeia } \\
\text { + Aspectos de outros temas: clima escolar, divisão } \\
\text { do tempo de trabalho e satisfação no trabalho }\end{array}$ & $\begin{array}{l}\text { Cinco temas principais: } \\
\text { - Liderança escolar, incluindo novos indicadores } \\
\text { sobre liderança distribuída / equipe } \\
\text { - Avaliação e feedback para professores } \\
\text { - Crenças pedagógicas, atitudes e práticas de ensino } \\
\text { dos professores, incluindo novos indicadores } \\
\text { sobre o perfil das práticas de avaliação dos alunos } \\
\text { - Formação de professores, incluindo } \\
\text { desenvolvimento profissional e novos indicadores } \\
\text { sobre a formação inicial de professores } \\
\text { - Os professores relataram sentimentos de } \\
\text { autoeficácia, satisfação no trabalho e clima nas } \\
\text { escolas e salas de aula em que trabalham }\end{array}$ \\
\hline
\end{tabular}

Fonte: OECD, 2009, pp. 21, 268-275; OECD, 2014a, pp. 28, 214-221

Ainda, essas principais características parecem levantar quantas perguntas podem responder em relação aos arranjos institucionais para o TALIS, os processos pelos quais a pesquisa foi desenhada e a formulação dessas perguntas. Na parte restante desta seção, apresentamos argumentos prévios quanto ao enquadramento, medição e venda de Professores de Qualidade ${ }^{\mathrm{TM}}$, que se baseiam em uma suposição específica sobre a natureza das evidências que as respostas “subjetivas" dos professores são enquadradas e subordinadas aos dados objetivos dos alunos avaliados pelo PISA.

Além disso, mostramos que os índices e itens presentes no questionário do TALIS sugerem que a pesquisa (TALIS) tem como viés a pedagogia construtivista e a flexibilização do trabalho do professor. Assim, apesar das aspirações ao programa, o TALIS não é tão abrangente quanto os temas políticos e como os números dos índices e itens sugerem. 


\section{O enquadramento das evidências}

A OCDE trabalha com a profissão docente com o aval da organização baseada em evidências políticas e com a codificação associada à transmissão do conhecimento, centrada na identificação das 'melhores práticas' as quais, por sua vez, medem e usam como base de aferição esse conhecimento (Ver: OECD; 2007). Teachers Matter (OCDE, 2005, p.14), portanto, chamam para a realização do ideal "transformar a docência em uma profissão rica em conhecimento”. O relatório TALIS 2008 (OCDE, 2009, p.3) inicia com a afirmação de que "educação ainda está longe de ser uma indústria do conhecimento no sentido de que suas próprias práticas ainda não estão sendo transformadas pelo conhecimento sobre a eficácia de suas práticas” e o relatório principal do TALIS 2013 (OCDE, 2014a) faz referências constantes a essas "evidências”.

No entanto, as próprias codificações de conhecimento ou "evidências" construídas nas ferramentas de medição do TALIS são apresentadas como ambíguas devido à sua natureza subjetiva:

Os resultados do TALIS são baseados em autorrelatos de professores e líderes escolares e, portanto, representam suas opiniões, percepções, crenças e descrições de suas atividades. Essa é uma informação poderosa porque fornece uma visão de como os professores percebem os ambientes de aprendizagem em que trabalham, o que os motiva e como as políticas que são colocadas em prática são realizadas na prática. Mas, como em qualquer dado autorreferido, essa informação é subjetiva e, portanto, difere dos dados coletados objetivamente. (OCDE, 2014a, p. 29)

Considerando a adoção da OCDE em adotar uma política baseada em evidências, observamos os esforços contínuos para forjar vínculos entre o TALIS e o PISA (OCDE, 2012). Diante disso, o TALIS parece servir a um maior propósito do que o desempenho dos alunos, conforme avaliado pelo PISA, com os dados mais subjetivos dos autorrelatos dos

professores, tornando-se subordinados aos dados objetivos do desempenho dos alunos. É, portanto, sintomático que os primeiros parágrafos do relatório principal do TALIS 2013 se referem ao PISA e não ao próprio TALIS (OCDE, 2014a, p. 3).

\section{A preferência pela pedagogia construtivista}

As conclusões do TALIS a respeito da crença dos professores sobre ensino e aprendizagem e os relatos de suas práticas em sala de aula se destacam por serem notavelmente vagos (OCDE, 2009, capítulo 4; OCDEa, capítulo 6, Rinne \& Ozga, 2013). Isso pode ser devido à justaposição desnecessária das crenças 'construtivistas' (“caracterizadas pela visão de professor facilitador da aprendizagem com mais autonomia 
aos estudantes") e visões de “ transmissão direta” (vê “o professor como instrutor, fornecendo informações e demonstrando soluções”) (OECD, 2009, p.269; OECD, 2014a, p. 217).

Todavia, o projeto pedagógico da OCDE está claramente ancorado pelo construtivismo; um princípio central que na realidade não existe independente das matérias que buscam isso. Em outras palavras, não existe outro mundo preexistente independente (OLSSEN, 1996). Esse viés em relação à pedagogia construtivista é simbolizado pela redução dos índices no TALIS 2013, para incluir apenas um índice sobre crenças construtivistas para obter as crenças dos professores sobre ensino e aprendizagem (OCDE 2014a, p.217; compare OCDE 2009, p.269).

\section{Emprego flexível}

A OCDE afirma que o TALIS dá "voz" aos professores. No entanto, ele pode contribuir para que os professores percam a voz coletiva ao longo do tempo. Devemos notar que o status profissional dos professores varia em todo o mundo. Na Europa, por exemplo, os professores podem ser distinguidos como funcionários públicos, funcionários públicos de carreira ou funcionários contratados (temporários), dependendo de acordos nacionais ou subnacionais (Comissão Europeia \& EACEA/Eurídice, 2013, p. 50). No geral, a OCDE afirma que o programa TALIS, no seu âmbito geral, reconhece as diferenças institucionais e ajuda a identificar as informações transculturalmente válidas e similares sobre as condições de trabalho dos professores e do ambiente de aprendizagem nas escolas (OCDE, 2014 a, p. 26).

Enfrentamos, portanto, uma contradição: a OCDE afirma que o TALIS reconhece que os sistemas educacionais são obrigados a refletir os contextos sociais e culturais, mas as recomendações políticas mostram que as diferenças na organização institucional devem ser anuladas com a maximização do "desempenho estudantil", como concebido e reformulado pela OCDE. Em sua discussão sobre negociação coletiva, o relatório Problemas dos Professores representa a contradição:

...os resultados contrastantes reforçam o ponto básico de que os acordos coletivos, como qualquer outro mecanismo para determinar os níveis de recursos escolares e seus usos, precisam, em última instância, ser avaliados em termos de impactos nos resultados dos alunos. (OCDE, 2005, p.146).

Entretanto, apesar das evidências contraditórias de pesquisa, o mesmo relatório reivindica "ter condições de trabalho mais flexíveis" (OCDE, 2005, p.162) como uma política prioritária e não permanente na situação profissional dos professores.

As questões dos professores fornecem as bases para o programa TALIS e a avaliação, feedback e diferenciação salarial continuam sendo questões proeminentes na pesquisa. Nesse contexto, parece omissão por parte do projeto que os principais relatórios da OCDE 
do TALIS 2008 e do TALIS 2013 não abordam o que várias diferenças nacionais ou subnacionais, na situação profissional, podem significar para os arranjos institucionais em relação a essas questões.

O TALIS é um grande exercício em termos de pesquisa. No entanto, os pontos acima mostram que o programa, sob a suposta objetividade, também é uma construção política, refletindo a negociação das preferências políticas pela OCDE e a gama de organizações e autoridades envolvidas nele.

\section{O Conjunto TALIS: os Orquestradores e Legitimadores do Professor de Qualidade $^{\mathrm{TM}}$}

Esta sessão tem como foco os orquestradores e legitimadores do Professor de Qualidade $^{\mathrm{TM}}$ - a OCDE, a Comissão Europeia, a Internacional da Educação (organização internacional que reúne os sindicatos de educação no mundo), e os atores políticos do setor privado no programa TALIS. Essas instituições foram selecionadas porque, destacando seu envolvimento na pesquisa, ajudam a explicar o enquadramento, a medida e a venda do Professor de Qualidade ${ }^{\mathrm{TM}}$, bem como propicia a oportunidade de adotar uma perspectiva mais distante e crítica sobre as estratégias dessas organizações.

No entanto, primeiro devemos delinear os arranjos institucionais básicos do programa TALIS. Para tanto, concebemos a gama de organizações e órgãos envolvidos na concepção, design e implementação do programa TALIS como 'conjunto TALIS' (ver Robertson \& Dale, 2015, para considerações teóricas sobre "conjuntos de educação"). Iria além dos limites deste artigo explorar em detalhes as relações internas e propriedades emergentes do conjunto TALIS como uma formação social, mas os seguintes grupos são alguns de seus principais constituintes:

- O Secretariado TALIS da OCDE tem a responsabilidade geral de gerenciar o programa.

- Em princípio, o TALIS é financiado através de autoridades governamentais, tipicamente ministérios da educação, de instituições políticas participantes. No entanto, a Comissão Europeia é, na verdade, o principal financiador, uma vez que subsidiou a participação dos membros da UE.

- Dentro da OCDE, há cinco entidades representativas engajadas com o TALIS. Esses órgãos são compostos por altos funcionários ou especialistas indicados por governos nacionais de países-membros ou não membros da OCDE.

- O Consórcio internacional TALIS é responsável pela coordenação e gestão da implementação em nível internacional. O encarregado nomeado para o TALIS 2013 foi a Associação Internacional para a Avaliação da Realização Educacional (AIE), com a Statistics Canada como subcontratada da AIE. 
- Por fim, gestores nacionais de projetos e de dados em centros nacionais implementaram o TALIS em instituições políticas participantes (OCDE 2014a, p.29; OCDE, 2015).

\section{OCDE e a Comissão Europeia: principais enquadramentos sobre Quality Teacher $^{\mathrm{TM}}$}

Para levar o programa TALIS adiante, os papéis da OCDE e da direção geral de educação e cultura (DGEAC) da Comissão Europeia (EC) não podem ser superestimados. Os entrevistados da OCDE assim como da DGEAC para este estudo estavam interessados em enfatizar que suas organizações são, antes de tudo, intergovernamentais para cooperação. No entanto, está claro que as duas organizações são atores políticos estratégicos, fortes, capazes de moldar a agenda política, refletindo nos mandatos políticos dados pelo Estado. Consequentemente, eles são, pelo menos em certa medida, "esperados a liderar" - nas palavras de um analista sênior da OCDE que entrevistamos - nas negociações nas quais as decisões são, em princípio, tomadas por consenso.

Por mais estreita que seja a parceria no TALIS e a colaboração em política educacional em geral (Comissão Europeia, 2012), a OCDE e a DG EAC tiveram papéis distintos no programa e seguiram estratégias diferentes. Assim, com sua reputação de principal 'grupo de pesquisa' para os países mais ricos do mundo e o principal fornecedor mundial de estatísticas educacionais (Henry, Rizvi, Lingard e Taylor 2001; Lawn \& Grek, 2012; Mahon \& McBride, 2008; Meyer \& Benavot, 2013; Woodward, 2009), a OCDE é o único autor principal da pesquisa. Enquanto isso, a Comissão Europeia e a DG EAC podem ser entendidas como as aliadas mais importantes da OCDE, mesmo com suas diferenças políticas.

A OCDE é a estrutura principal do Professor de Qualidade ${ }^{\mathrm{TM}}$, no conjunto TALIS, desde que a pesquisa foi originalmente elaborada dentro da organização que abriga as principais atividades relacionadas ao seu design e desenvolvimento. Dentro dela, o Conselho de Países Participantes da TALIS (Conselho TALIS) destaca-se como o órgão mais importante para a tomada de decisão multilateral sobre a TALIS. As principais questões foram, pela primeira vez, para as duas primeiras rodadas da TALIS, negociadas também no Comitê de Política Educacional da OCDE e, em alguns casos, no Conselho da OCDE. Mas é no Conselho TALIS que as decisões estão sendo tomadas em relação aos objetivos das políticas para a pesquisa e onde os padrões para coleta e relatório de dados são estabelecidos. O Conselho TALIS está, portanto, no cerne do conjunto TALIS.

O Conselho TALIS foi formalmente criado em $1^{\circ}$ de janeiro de 2007 para ser abolido em 31 de dezembro de 2015 (OCDE, 2015). Suas características gerais em termos de responsabilidades e constituintes permaneceram estáveis nas rodadas de 2008 e 2013 da TALIS. A partir da próxima rodada, TALIS 2018, o programa será 'atualizado' na hierarquia institucional da OCDE, tornando-se o chamado programa da Parte II desfrutando, assim, de um status semelhante ao do PISA. Entre outras coisas, é provável 
que esse novo status implique um compromisso em longo prazo mais estável com a participação e o financiamento dos países para o programa TALIS em geral, e que o Conselho TALIS desfrutará de mais independência na tomada de decisões.

O Conselho TALIS é composto por representantes do governo de cada entidade política participante e de várias organizações. A Comissão Europeia (CE) é representada por oficiais de políticas da Direção Geral de Educação e Cultura (DG EAC), e a UNESCO tem o status de observadora permanente. Além disso, o Comitê Consultivo para Empresas e Indústria (BIAC) e o Comitê Consultivo para Sindicatos da OCDE (TUAC, o mecanismo formal da OCDE para o diálogo social com sindicatos) participaram das negociações (OCDE, 2009, pp. 303-305; OCDE, 2015; OCDE 2014, pp. 434-436; entrevistas com analistas da OCDE, oficiais de política da DG EAC e representantes de EI).

Como organização coordenadora do TALIS, a OCDE supervisiona o trabalho no Conselho TALIS e é o principal fornecedor de materiais para reuniões. Além disso, a OCDE está obviamente interessada em aumentar ainda mais seu perfil com a adesão de países-membros e não membros da OCDE. Assim, o TALIS é complementado por outras atividades da OCDE. O PISA, portanto, ficou na sombra do TALIS, com a OCDE explorando continuamente possíveis 'sinergias' entre os dois programas e incentivando os países participantes, principalmente relutantes, a se inscreverem no chamado TALIS-PISA link no TALIS 2013 (entrevistas com analista da OCDE e alto funcionário do IE; OCDE, 2012). O vínculo implica que as populações da amostra TALIS nos países participantes estejam alinhadas com as do PISA. Oito países incorporaram o link TALIS-PISA: Austrália, Finlândia, Letônia, México, Portugal, Romênia, Cingapura e Espanha (OCDE, 2014a, p.27).

O TALIS também é conhecido por outras atividades da OCDE sobre professores. O mais notável deles são as Cúpulas Internacionais anuais sobre a Profissão Docente. A primeira dessas cúpulas foi convocada em Nova Iorque, em 2011, pelo Departamento de Educação dos Estados Unidos, a OCDE e a IE. A iniciativa para a cúpula foi tomada após o TALIS 2008, e o diretor adjunto de educação da OCDE, Andreas Schleicher, comprometeu-se a redigir o relatório de base da Cúpula (OCDE, 2011), além de desempenhar o papel de criador da agenda.

Isso nos leva a um dos aspectos mais intrigantes do programa TALIS, que diz respeito à posição ambígua em que o programa coloca a profissão de professor. Assim, os professores são reconhecidos simultaneamente como uma força de trabalho essencial e criticados por não cumprirem suas responsabilidades. Por outro lado, a OCDE - desde o relatório Teachers Matter - enfatizou a importância de envolver a profissão de professor em políticas (OCDE, 2005, pp. 15, 214) e argumenta que procura dar a "professores e líderes de escolas em todo o mundo uma voz para falar sobre suas experiências" (OCDE, 2014a, p. 3). Isso claramente marca um afastamento dos discursos neoliberais (Robertson, 2013, p. 78). Por outro lado, a exclusão dos professores dos debates continua, com a OCDE confiante de que tem as respostas. Mais recentemente, o secretário-geral da OCDE, Angel Gurría, afirmou que "os resultados do TALIS 2013 mostram que precisamos colocar os professores no caminho do sucesso imediatamente” (OCDE, 2014a, p. 3). 
Desde a fundação da OCDE em 1961, ela tenta informar e influenciar políticas, visando tomadores de decisão, funcionários do governo e organizações da sociedade civil (Mundy, 2007). Portanto, é notável que ela, após o TALIS 2013, tenha procurado atingir professores e diretores escolares diretamente, publicando um Guia do Professor (OCDE 2014b). As publicações da OCDE que se dirigem diretamente aos professores são muito raras e somente em épocas de ameaça à segurança, por exemplo, durante a Guerra Fria e o clima das corridas espaciais de meados da década de 1960, foi que se publicou o Guia de Física da OCDE (OCDE, 1965; ver também Tröhler 2013).

Marcado como "selfie global" pelos professores (OCDE, 2014b, p.7), o guia de 28 páginas apresenta recomendações sobre como os dados do TALIS podem ser usados por professores e dirigentes de escolas para ter maior impacto nas salas de aula. De acordo com um analista da OCDE que entrevistamos, o guia faz parte de uma estratégia mais ampla para alcançar diretamente professores e líderes de escolas, reconhecendo que os principais relatórios do TALIS provavelmente não serão lidos por professores ou dirigentes escolares. Aumentar a conscientização sobre as atividades da TALIS e da OCDE de maneira mais geral visa obter a adesão de profissionais da escola e aumentar o apoio deles nas próximas rodadas da TALIS.

Embora atualmente disponível apenas em três idiomas (inglês, francês e espanhol), o guia mostra que a OCDE, como ator global, também está se aprofundando nos microespaços locais e, ao fazer isso, perpassa por governos e sindicatos de professores nacionalmente localizados. Essa tendência é ainda mais indicada pelo recente lançamento do Teste para Escolas da OCDE, baseado no PISA e direcionado a escolas "interessadas em benchmarking internacional" para "obter resultados no grau de escolaridade para fins de benchmarking e melhoria escolar” (OCDE, 2014c).

No que diz respeito à CE e à DG EAC, o TALIS é um dos primeiros projetos em que eles trabalharam em estreita colaboração com a OCDE no campo da educação. A CE, e mais especificamente a DG EAC, desempenhou um papel fundamental nos estágios iniciais do TALIS, particularmente na implantação do programa. Isso deve ser entendido no contexto da Estratégia da UE para Lisboa 2000-2010, em que a educação e a formação receberam um novo papel de destaque para "tornar a Europa a economia baseada no conhecimento mais competitiva e dinâmica do mundo” (Conselho da União Europeia, 2000). Com base nas discussões em grupos de trabalho de especialistas nacionais criados pela DG EAC, as conclusões do Conselho Europeu acordadas pelos ministros de Educação dos Estados-membros em 2005 e 2007 (Conselho da União Europeia, 2005, 2007) deram à Comissão Europeia e à DG EAC mandatos para prosseguir a cooperação com a OCDE em matéria de TALIS, e incentivar os Estados-membros a participarem, a fim de ajudar a cobrir as necessidades de dados no monitoramento dos progressos em direção aos objetivos da Estratégia de Lisboa. As conclusões do Conselho de 2007 também conferiram à DG EAC o mandato de subsidiar os Estados-membros por sua participação no TALIS.

A CE e a DG EAC, em conformidade com o mandato conferido pelas conclusões do Conselho de Ministros Europeu, entraram assim no programa TALIS com prioridades políticas distintas. Durante as duas primeiras rodadas do TALIS, a prioridade principal foi o 
desenvolvimento profissional dos professores, e a DG EAC buscou isso com êxito, uma vez que o desenvolvimento profissional foi coberto nas duas rodadas do TALIS, nas quais a maior parte dos participantes foi composta pelos Estados-membros da UE, indubitavelmente incentivados pelas DG EAC, oferecendo-se para subsidiá-los com 75\% das taxas de participação do TALIS. As preferências políticas distintas da CE e da DG EAC também se refletem no fato de que elas prepararam ou encomendaram seus próprios relatórios com um foco europeu no TALIS (Scheerens, 2010; Direção Geral de Educação e Cultura, 2014).

Um funcionário sênior que entrevistamos na DG EAC apontou que, antes de cada reunião no Conselho TALIS, a DG EAC realizava reuniões de coordenação para os paísesmembros da UE que participavam do TALIS. Dado que apenas gozava de estatuto de observador no Conselho da TALIS, era imperativo para a DG EAC que os Estadosmembros da UE participantes levassem adiante a agenda da CE nas reuniões do Conselho da TALIS, ficando claro aos Estados-membros que a sua participação no Conselho só seria subsidiada pela CE se conseguissem incluir o desenvolvimento profissional docente na pesquisa. No entanto, esse funcionário também observou que a OCDE abraçou o interesse da CE na TALIS e procurou acomodar a TALIS, tanto quanto possível, com os objetivos da CE. Essa estreita parceria de trabalho também se refletiu no fato de que os resultados iniciais do TALIS 2008 foram lançados no edifício da CE Berlaymont em Bruxelas, em julho de 2009, uma vez que a OCDE está sediada em Paris.

Enquanto as organizações internacionais OCDE e CE, à sua maneira, levaram o programa TALIS adiante, os arranjos institucionais do TALIS também foram projetados para permitir às autoridades estaduais estender seu horizonte de influência muito além de sua própria jurisdição. A tomada de decisões no Conselho TALIS ocorre formalmente com base nos votos dos países participantes. Além disso, são os países participantes que se inscreveram para uma rodada TALIS desde o início e são convidados a selecionar temas e indicadores de políticas por meio de um exercício de classificação prioritária. Para o TALIS 2013, havia 20 temas em potencial e 94 indicadores. Os exercícios de classificação de prioridade têm como objetivo fornecer uma pesquisa focada que reflita as prioridades das políticas das instituições políticas participantes (OCDE, 2013, pp. 9-13).

Finalmente, enquanto a OCDE como organização tem um forte interesse em estreitar os vínculos entre o TALIS e o PISA, os países participantes, desde o lançamento do TALIS, tendem a insistir em tratá-los como programas separados, com identidades distintas em termos políticos e metodológicos (entrevistas com analista da OCDE e alto funcionário da DG EAC). Sob esse prisma, podemos considerar isso um indicativo da capacidade da OCDE de obter “adesão” dos governos por seus projetos mais experimentais que, apesar do ceticismo geral, oito países se inscreveram no link TALIS-PISA no TALIS 2013.

\section{Educação internacional: legitimando o Professor de Qualidade}


Como principal organização que trabalha pelos interesses dos docentes no TALIS, a Internacional da Educação (IE) recebeu um amplo mandato para negociar em nome de suas organizações afiliadas no Conselho TALIS. A IE participa das reuniões da Diretoria do TALIS desde que foi iniciada em 2006 e recebeu o status de observador permanente em 2009. Para atingir esse status, a IE foi consultada durante a escrita de alguns capítulos e aproveitou a oportunidade para enviar comentários e ideias.

Deve-se observar que as afiliadas da IE financiam e decidem as prioridades políticas para as atividades da IE e da TUAC (CARTER, STEVENSON E PASSY, 2010). Os representantes da TUAC que participam das reuniões do Conselho TALIS relataram a um subgrupo de organizações afiliadas da IE que foi criado através do Grupo de Trabalho sobre Políticas de Educação, Treinamento e Emprego da TUAC. Consequentemente, as afiliadas da IE foram incentivadas a mobilizar o apoio à TALIS entre seus membros (EDUCATION INTERNATIONAL, 2012).

Todos os funcionários da IE, da OCDE e da DG EAC caracterizaram sua cooperação no TALIS como construtiva e funcional. No entanto, o envolvimento da IE na OCDE foi inicialmente motivado por desacordos. De acordo com um funcionário sênior da IE, o relatório Teachers Matter (OECD 2005) levou a instituição a reagir devido a algumas das recomendações políticas da OCDE. Em particular, a questão dos salários com base no desempenho dos professores destacou-se como uma 'linha vermelha' a ser ultrapassada pela IE e suas afiliadas. Assim, a IE procurou envolver-se no Conselho TALIS para tentar influenciar a construção do conhecimento gerado no programa e, de maneira mais geral, contestar as evidências apresentadas por atores cada vez mais poderosos, como OCDE, CE, Pearson Education e McKinsey \& Company (EDUCATION INTERNATIONAL, 2012; EDUCATION INTERNATIONAL, 2007).

Poderíamos dizer que a IE vê o TALIS como uma construção essencialmente política, através da qual a priorização de certos temas políticos, indicadores e formulação de perguntas deve conter um viés em relação a noções particulares de educação, sociedade e o papel e as condições de trabalho dos professores. Consequentemente, um ponto focal para a IE no Conselho TALIS até agora tem sido a formulação dos itens do questionário TALIS.

No entanto, ao avaliar o impacto do envolvimento da IE na direção da TALIS, é imperativo ressaltar que os funcionários da OCDE e da IE enfatizam que a influência dos sindicatos de professores permaneceu limitada. O mandato formal para a OCDE vem dos governos-membros e o papel da IE como observador permanente no Conselho TALIS não pode, portanto, ser comparado ao dos governos, formal e informalmente. Assim, é evidente que a IE não participe do exercício de classificação prioritária da TALIS de temas e indicadores de políticas. Além disso, os representantes da TUAC são excluídos de participar de algumas das discussões no Conselho TALIS.

Em outras palavras, a IE tem oportunidades muito limitadas para enquadrar e moldar a direção do TALIS; em vez disso, agiu ou foi usada pela OCDE para legitimar a 'venda' do produto Professor de Qualidade ${ }^{\mathrm{TM}}$ da OCDE. Ao mesmo tempo, com o seu engajamento, a IE aprova a pesquisa como um instrumento de medição relevante e incentiva suas organizações afiliadas a apoiá-la. Em resumo, a IE oferece assistência crucial na venda do 
programa e na promoção de uma marca do Professor de Qualidade ${ }^{\mathrm{TM}}$ que não é de sua autoria. O programa TALIS depende das taxas de resposta dos professores e continua sendo uma questão em aberto se essas taxas poderiam ser alcançadas se a IE e os sindicatos de professores aconselhassem seus membros a não participarem da pesquisa.

Isso levanta uma questão sobre os mecanismos pelos quais a profissão docente é representada no TALIS e a reformulação da relação vertical entre a IE e suas afiliadas. Ao participar e promover um envolvimento em evolução da IE nas duas rodadas do TALIS por meio do TUAC, a OCDE também está reorientando a IE em direção às agendas que estão sendo avançadas nesse novo espaço de política global e, portanto, mais distante daquela dos membros afiliados à IE.

De fato, em entrevistas, os funcionários da IE apontam que estão cientes do risco de se envolverem na versão distintiva da OCDE da política baseada em evidências e do risco associado de despolitização do trabalho docente. Nas palavras de um funcionário sênior da IE, a organização vê isso como um perigo geral em que "as evidências sequestrem o diálogo social” e prejudiquem o desenvolvimento de arranjos institucionais para a negociação coletiva.

Vemos que o conjunto TALIS é constituído por dinâmicas complexas, partindo do pressuposto de que problemas comuns e soluções podem ser identificados com relação ao trabalho docente em escala global. Isso também se aplica à autonomia profissional e à maneira como os professores são capazes de apresentar suas ideias e exercer controle sobre seu trabalho. A IE recebeu um mandato de suas afiliadas para participar do TALIS, mas a organização é vulnerável à crítica também direcionada à OCDE e à UE, a saber, o déficit democrático em termos de representação dos diversos interesses de seus membros. A IE está tentando fazer sua voz ser ouvida em escala global, mas a estrutura vertical que deve permitir a consulta às entidades afiliadas como parte do trabalho em andamento da TALIS parece tão ambígua e opaca quanto as que existem entre os países-membros da CE e da UE.

\section{Empresas e fundações: vendendo o Quality Teacher ${ }^{\mathrm{TM}}$ da OCDE}

As empresas e fundações do setor privado não parecem estar muito envolvidas no enquadramento do TALIS. O mecanismo formal de consulta aos interesses do setor privado na OCDE, o Comitê Consultivo para Empresas e Indústria (BIAC), manteve um perfil discreto nas reuniões do Conselho do TALIS, de acordo com o pessoal da OCDE, DG EAC e EI.

Alguns dos Centros Nacionais que implementaram a pesquisa TALIS incluíram empresas privadas e, pelo menos no caso da Inglaterra na TALIS 2013, o Gerente Nacional de Projetos, empregado por uma empresa privada de educação e tecnologia, usou a possibilidade (oferecida para todas as instituições políticas participantes) para propor perguntas extras para a pesquisa em inglês, que foram aprovadas pelo Grupo Diretor nacional. No entanto, em termos da estrutura e medição geral do TALIS e Professor de Qualidade $^{\mathrm{TM}}$, essa influência parece ser marginal. 
Mais importante, as organizações do setor privado são muito ativas na criação de perfil e na venda do TALIS usando dados, interpretando e discutindo resultados. Isso é visível na série coordenada de eventos em torno do lançamento dos resultados do TALIS. Como no caso de outros produtos, a OCDE aspira claramente a transformar esses lançamentos em 'eventos mundiais' (SOBE, 2013; STICHWEH, 2013).

Os resultados do TALIS 2013 foram apresentados oficialmente em Tóquio, em 25 de junho de 2014, numa reunião informal de ministros da Educação da OCDE (também participou o diretor-geral da DG EAC). Na mesma data, o webinar mundial ao vivo "Education Fast Forward 10: Better Teaching for Better Learning", promovido pela empresa de tecnologia Promethean Planet, conectou estúdios em Atlanta, Boston, Londres, Paris, Tóquio e outros lugares para formar um debate entre o que foi rotulado como 'especialistas em educação global', notavelmente dominado por consultorias e fundações baseadas na América do Norte ou na Inglaterra, como a Fundação Bill \& Melinda Gates, TSL Education (agora TES Global), Unidade de Inovação e Promethean. A OCDE e a UNESCO também estiveram representadas, juntamente com renomados acadêmicos globais, como o professor Michael Fullan e o professor Pasi Sahlberg. Em termos de governos nacionais, apenas o Departamento de Educação dos EUA estava representado. Por fim, John Bangs, presidente da TUAC, participou como a voz dos sindicatos de professores (Education Fast Forward, 2014).

Nesse sentido, consultorias privadas e filantropos corporativos parecem atuar principalmente na periferia do conjunto TALIS. No contexto do programa TALIS, o empreendedorismo empresarial, inovação e realização de lucros baseiam-se na disseminação e interpretação (portanto, potencialmente reenquadrando o TALIS) dos dados gerados sob a tutela da OCDE.

Devemos notar que os atores do setor privado têm perfis muito diferentes em termos de preferências políticas, estratégias e horizontes de ação (Ball, 2001; Robertson\& Verger, 2012). No entanto, eles compartilham a ideia de que suas atividades, seja negócios com fins lucrativos ou filantropia de risco, produzem recomendações políticas com base em dados da TALIS que, por sua vez, podem muito bem sustentar novos produtos e serviços. Portanto, atores da política do setor privado se engajam em uma relação simbiótica com a OCDE, da orientação de suas recomendações, uma vez que eles dependem simultaneamente de programas de pesquisa pagos publicamente, como o TALIS, e ajudam a legitimar esses programas, elevando seu perfil geral. Em outras palavras, eles ajudam a vender a marca de Professor de Qualidade ${ }^{\mathrm{TM}}$ implícito no TALIS.

A relação simbiótica será reforçada provavelmente pela iniciativa da OCDE nas cúpulas anuais da indústria global da educação (OCDE, 2014d). É notável que estas pesquisas sejam destinadas a complementar as Cúpulas Internacionais anuais sobre a Profissão Docente.

\section{Observações Finais: Professor de Qualidade ${ }^{\mathrm{TM}}$}


Começamos este artigo apontando para o fato de que professores em todo o mundo têm sido, cada vez mais, questionados sobre a natureza de seu trabalho e, particularmente, sobre a forma e conteúdo de sua prática pedagógica. A questão dos professores é argumentada e poucos discordariam disso. Mas podemos perguntar sobre o que realmente está nas agendas da OCDE, da Comissão Europeia e de outros atores políticos envolvidos no que chamamos de conjunto TALIS.

Olhamos mais de perto para a marca Professor de QualidadeTM que está no centro do projeto TALIS da OCDE e argumentamos que o Professor de Qualidade ${ }^{\mathrm{TM}}$ perseguido através do programa destina-se a endossar a pedagogia construtivista e trabalhar um regime de emprego flexível. Mostramos que os índices e itens que tratam da pedagogia e do regime de trabalho nas duas primeiras rodadas do TALIS são tão simplistas que as respostas da pesquisa não podem questionar ou contradizer essas preferências políticas, muito menos expô-las. Além disso, o TALIS é enquadrado pelo PISA, a empresa mais bem-sucedida em pesquisa educacional comparativa de todos os tempos, e as respostas da pesquisa TALIS estão, portanto, subordinadas à avaliação do PISA sobre o desempenho dos alunos como concebida e marcada pela OCDE.

Descompactamos o conjunto TALIS e apontamos que a OCDE e a Comissão Europeia enquadraram, mediram e venderam a marca Professor de Qualidade ${ }^{\mathrm{TM}}$ com seus objetivos distintos, que o sindicato global de professores, a IE, legitimou o enquadramento TALIS no trabalho docente e as políticas que o cercam em nível global e que as empresas privadas e fundações são muito ativas na tentativa de fazer negócios com base nos dados do TALIS.

Como nossa análise torna evidente, esses desenvolvimentos refletem uma grande transformação em curso com o objetivo de reenquadrar e redimensionar onde e como as decisões são tomadas em torno da pedagogia dos professores e da natureza da profissão de forma mais geral. O TALIS foi lançado como um grande esforço de coleta de dados destinado a reformar a profissão docente em todo o mundo. Como uma tecnologia de professores governantes globalmente, promete aos países participantes uma riqueza de dados para pesquisas comparativas destinadas a ajudar os países a criar professores mais eficazes e economias mais competitivas baseadas no conhecimento.

Entretanto, detectamos uma contradição imensa nesse enquadramento apertado do professor de qualidade - na verdade, há pouco espaço para discrição, inovação ou risco todos os elementos na aprendizagem no local de trabalho que provavelmente levarão a níveis mais elevados de aprendizagem social, satisfação no trabalho, produtividade e inovação do sistema (LUNDVALL \& LORENZ, 2015; SAHLBERG, 2011). Professor de Qualidade ${ }^{\mathrm{TM}}$ como atualmente enquadrado, medido e vendido através do TALIS coloca limites sobre as próprias capacidades dos professores com as que pretendem se preocupar. Portanto, essa marca particular de profissionalismo docente provavelmente prejudicará a mesma coisa que espera alcançar - professores e alunos mais inovadores, criativos e aprendizes para a economia do conhecimento. 


\section{Notas}

1. Este artigo foi traduzido por Rosângela Alves Basso, com a autorização dos autores, a partir de um capítulo de livro publicado em inglês: Sorensen, T.B., \& Robertson, S.L. (2018), The OECD program TALIS and Framing, Measuring and Selling Quality Teacher ${ }^{\mathrm{TM}}$ in M. Akiba \& G.K. Le Tendre (eds.). Routledge International Handbook of Teacher Quality and Policy. Routledge.

2. Foi realizada outra edição da TALIS em 2018. Nota dos editores.

3. A Classificação Padrão Internacional de Educação (ISCED) foi lançada pela UNESCO em 1976 para facilitar comparações de estatísticas educacionais e indicadores entre países com base em definições uniformes e acordadas internacionalmente. O ISCED já foi revisto duas vezes.

\section{Referências}

BALL, S. J. Global education Inc: New policy networks and the neo-liberal imaginary. London: Routledge, 2012.

CAENA, F. Teacher Competence Frameworks in Europe: Policy-as-discourse and policy-as-practice. European Journal of Education, 49(3), 311-331, 2014.

CARTER, B., Stevenson, H., \& Passy, R. Industrial Relations in Education: Transforming the School Workforce. Abingdon, Oxon: Routledge, 2010.

CONNELL, R. Good teachers on dangerous ground: Towards a new view of teacher quality and professionalism. Critical Studies in Education, 50(3), 213-229, 2009.

COUNCIL OF THE EUROPEAN UNION. PRESIDENCY CONCLUSIONS. Lisbon European Council, 23 and 24 March 2000. Retrieved from http://www.europarl.europa.eu/summits/lis1_en.htm

COUNCIL OF THE EUROPEAN UNION. COUNCIL CONCLUSIONS of 24 May 2005 on new indicators in education and training. 2005/C141/04. Retrieved from http://eur-lex.europa.eu/legalcontent/EN/TXT/HTML/?uri=CELEX:52005XG0610(01)\&from=EN

COUNCIL OF THE EUROPEAN UNION. COUNCIL CONCLUSIONS on a coherent framework of indicators and benchmarks for monitoring progress towards the Lisbon objectives in education and training.2802nd Education, Youth and Culture Council meeting, Brussels, 24-25 May 2007. Retrieved fromhttp://www.consilium.europa.eu/uedocs/cms_Data/docs/pressdata/en/educ/94290.pdfDirectorate General for Education and Culture (2014).

THE TEACHING AND LEARNING INTERNATIONAL SURVEY (TALIS): Main findings from the survey and implications for education and training policies in Europe, 2013. Retrieved from http://ec.europa.eu/education/library/reports/2014/talis_en.pdf

EDUCATION FAST FORWARD.EFF10: Better Teaching for Better Learning, 2014. Retrieved from http://www.effdebate.org/debates/previous-debates/eff10-better-teaching-for-better-learning/

EDUCATION INTERNATIONAL.Education International Guide to PISA 2006, 2007. Retrieved from http://download.ei-ie.org/docs/IRISDocuments/Research\%20Website\%20Documents/2009-00032-01-E.pdf

EDUCATION INTERNATIONAL.TALIS: EI ensures that teachers' concerns are considered, 2012.

Retrieved from http://www.ei-ie.org/en/news/news_details/2241 
European Commission. Framework for collaboration between the European Commission and the OECD in the field of education, 2012. Retrieved fromhttp://ec.europa.eu/archives/commission_20102014/vassiliou/documents/20120911-framework-for-collaboration-education-oecd_eac.pdf

EUROPEAN COMMISSION \& EACEA/EURYDICE. Key Data on Teachers and School Leaders in Europe, 2013. Edition. Luxembourg: Publications Office of the European Union.

HENRY, M., RIZVI, F., LINGARD, R., \&TAYLOR, S. Education, Globalisation and the OECD. London and New York: Routledge, 2001.

ILO \&UNESCO. Recommendation Concerning the Status of Teachers, 1966. Retrieved fromhttp://unesdoc.unesco.org/images/0016/001604/160495e.pdf

INTERNATIONAL TASKFORCE ON TEACHERS FOR EDUCATION FOR ALL. Teacher Policy Development Guide, 2014. Paris: UNESCO.

LAWN, M. \& GREK, S. Europeanizing Education: Governing a new policy space. Oxford: Symposium, 2012.

LUNDVALL, B.-Å. \& LORENZ, E. Toward a European Strategy for the Globalising Learning Economy. Paper presented at the ECPR-conference in Montreal, August 26-29, 2015.

MACBEATH, J. Future of Teaching Profession, 2012. Retrieved from http://download.eiie.org/Docs/WebDepot/EI\%20Study\%20on\%20the\%20Future\%20of\%20Teaching\%20Profession.pdf

MAHON, R. \& MCBRIDE, S. The OECD and Transnational Governance, Vancouver: UBC, 2009.

MEYER, H-D. \& BENAVOT, A. PISA, Power and Policy: The emergence of global educational governance. Oxford: Symposium, 2013.

MUNDY, K. Global governance, educational change. Comparative Education, 43(3), 339-357, 2007.

OECD. Teaching Physics today. Paris: OECD, 1965

OECD. Teachers Matter: Attracting, Developing and Retaining Effective Teachers, Education and Training Policy, 2005. Retrieved

fromhttp://www.oecd.org/education/preschoolandschool/attractingdevelopingandretainingeffectiveteacher s-finalreportteachersmatter.htm

OECD. Creating Effective Teaching and Learning Environments: First Results from TALIS, 2009. Retrieved from http://www.oecd.org/edu/school/43023606.pdf

OECD. Building a High Quality Teaching Profession: Lessons from around the World, 2011. Retrieved from http://www2.ed.gov/about/inits/ed/internationaled/background.pdf

OECD. The synergies between TALIS and PISA. EDU/EDPC (2012) 26. 28 Nov 2012. Retrieved fromhttp://www.oecd.org/officialdocuments/publicdisplaydocumentpdf/?cote=EDU/EDPC(2012)26\&doc Language $=$ En

OECD. Teaching and Learning International Survey TALIS 2013 Conceptual framework, 2013. Retrieved fromhttp://www.oecd.org/edu/school/TALIS\%20Conceptual\%20Framework_FINAL.pdf

OECD. TALIS 2013 Results: An international perspective on teaching and learning, 2014a. Retrieved from http://www.oecd-ilibrary.org/education/talis-2013-results 9789264196261-en

OECD. A Teachers' Guide to TALIS 2013, 2014b. Retrieved from http://www.oecd.org/edu/school/TALISTeachers-Guide.pdf

OECD. PISA-based Test for Schools - FAQ, 2014c. Retrieved fromhttp://www.oecd.org/pisa/aboutpisa/pisabased-test-for-schools-faq.htm

OECD. Proposal for an annual summit of the global education industry. EDU/CERI/CD (2014)19. Presented in the CERI Governing Board October 30-31, 2014d.

OECD. On-Line Guide to OECD Intergovernmental Activity, 2015. Retrieved from http://webnet.oecd.org/oecdgroups/ 
OLSSEN, M. Radical Constructivism and Its Failings: Anti-realism and Individualism. British Journal of Educational Studies, 44(3), 275-95, 1996.

PAPADOPOULOS, G. S. Education 1960-1990: The OECD Perspective. Paris: OECD, 1994.

RINNE, R. \& OZGA, J. The OECD and the Global Re-Regulation of Teachers' Work: Knowledge-Based Regulation Tools and Teachers in Finland and England. In T. Seddon \& J. Levin (Eds.), World Yearbook of Education 2013. Educators, Professionalism and Politics: Global Transitions, National Spaces and Professional Projects (pp. 97-116). Abingdon, Oxon: Routledge.

ROBERTSON, S.L. Placing teachers in global governance agendas. Comparative Education Review, 56(4), 584-607, 2012.

ROBERTSON, S. L. Teachers' Work, Denationalisation, and Transformations in the Field of Symbolic Control: A Comparative Account. In T. SEDDON \&J. LEVIN (Eds.), World Yearbook of Education. Educators, Professionalism and Politics: Global Transitions, National Spaces and Professional Projects (pp. 77-96), 2013. Abingdon, Oxon: Routledge, 2013.

ROBERTSON, S. L., \& DALE, R. Toward a 'Critical Cultural Political Economy' Account of the Globalising of Education. Globalisation, Societies and Education,13(1), 149-170, 2015.

ROBERTSON, S. L., \& SORENSEN, T.B. (no prelo). Reframing Teachers' Work for Global Competitiveness: New Global Hierarchies in the Governing of Education. Educational Researcher.

ROBERTSON, S. L., \& VERGER, A. Governing education through Public Private Partnerships. In S.L. ROBERTSON, K. MUNDY, A. VERGER, \& F. MENASHY (Eds.), Public Private Partnerships in Education: New Actors and Modes of Governance in a Globalizing World (pp. 21-42). Cheltenham: Edward Elgar, 2012.

SAHLBERG, P. Fourth Way of Finland. Journal of Educational Change,12(2), 173-185, 2011.

SASSEN, S. Globalization or denationalization? Review of International Political Economy, 10(1), 1-22, 2003.

SCHEERENS, J. Teachers' Professional Development Europe in international comparison: An analysis of teachers' professional development based on the OECD's Teaching and Learning International Survey (TALIS). Luxembourg: Office for Official Publications of the European Union, 2010. Retrieved from http://doc.utwente.nl/92610/1/NC8010244ENC_002.pdf

SCHLEICHER, A. Schools for 21st-Century Learners: Strong Leaders, Confident Teachers, Innovative Approaches, International Summit on the Teaching Profession. OECD Publishing, 2013. Retrieved fromhttp://dx.doi.org/10.1787/9789264231191-en

SOBE, N.W. Teacher professionalization and the Globalization of Schooling. In T. SEDDON \&J. LEVIN (Eds.), World Yearbook of Education 2013. Educators, Professionalism and Politics: Global Transitions, National Spaces and Professional Projects (pp. 42-54). Abingdon, Oxon: Routledge, 2013.

STICHWEH, R. The Eigen structures of World Society and the Regional Cultures of the World. In I. ROSSI (Ed.), Frontiers of Globalization Research: Theoretical and Methodological Approaches(pp.133-149). New York: Springer, 2008.

TRÖHLER, D. (2013). The OECD and Cold War Culture: thinking historically about PISA. In H-D. MEYER \& A. BENAVOT (Eds.), PISA, Power and Policy: The emergence of global educational governance(pp. 141-161). Oxford: Symposium, 2013.

WOODWARD, R. The Organization for Economic Cooperation and Development. London and New York: Routledge, 2009.

WORLD BANK (2012). SABER: Systems Approach for Better Education Results. What Matters Most in Teacher Policies? A Framework for Building a More Effective Teaching Profession, 2012. Retrieved from http://siteresources.worldbank.org/EDUCATION/Resources/278200-1290520949227/SABER-TeachersFramework-Updated_June14.2012.pdf 


\section{Correspondência}

Tore Sorensen: É atualmente pesquisador de pós-doutorado do ERC Starting Grant Project Teachers Careers no Institute for the Analysis of Change in Contemporary and Historical Societies (IACS) na Univerisdade de Louvain-la-Neuve, Bélgica.

E-mail: tore.sorensen@uclouvain.be

Orcid: 0000-0003-0982-5685

Susan Robertson: É professora de Sociologia da Educação na Faculdade de Educação da Universidade de Cambridge no Reino Unido. Sua pesquisa foi financiada por vários organismos, incluindo o ESRC, a Comissão Europeia e a Open Society Foundations, e foi consultora especialista sênior da DG Educação e Cultura da Comissão Europeia. Ela é editora-chefe da revista Globalisation, Societies and Education.

E-mail: slr69@cam.ac.uk

Orcid: 0000-0002-6757-8718

Texto publicado em Currículo sem Fronteiras com autorização dos autores 